\title{
An ultra-dispersive, nonprecious metal MOF-FeZn catalyst with good oxygen reduction activity and favorable stability in acid
}

\author{
Qing Zhao ${ }^{1}$, Cheng Wang ${ }^{1, *}\left(\mathbb{D}\right.$, Haifeng Wang ${ }^{2}$, and Jianlong Wang ${ }^{1}$ \\ 'Zhang Jiagang Joint Institute for Hydrogen Energy and Lithium-Ion Battery Technology, INET, Tsinghua University, Beijing, \\ People's Republic of China \\ ${ }^{2}$ Fenergy Company Ltd.,, Beijing, People's Republic of China
}

Received: 6 August 2020

Accepted: 9 January 2021

Published online:

1 February 2021

(C) The Author(s) 2021

\begin{abstract}
Development of the more stable nonprecious oxygen reduction reaction (ORR) catalyst is of great significance nowadays. Herein, a high-performance irondoped integral uniform macrocyclic organic framework (MOF-FeZn) catalyst is synthesized through a combined hydrothermal and pyrolysis process, showing favorable ORR activity and stability in acid. This as-synthesized MOF-FeZn catalyst displays high porous and graphitic structures with sufficient catalytic active dopants of pyridinic $\mathrm{N}, \mathrm{Fe}-\mathrm{N}$, pyrrolic $\mathrm{N}$, graphitic $\mathrm{N}$, making it a promising ORR candidate catalyst with high electrochemical stability. The onset potential, half-wave potential and limited diffusion current density of MOFFeZn are $0.93 \mathrm{~V} @ 0.1 \mathrm{~mA} \mathrm{~cm}{ }^{-2}, 0.768 \mathrm{~V} @ 2.757 \mathrm{~mA} \mathrm{~cm}^{-2}$ and $5.5 \mathrm{~mA} \mathrm{~cm}{ }^{-2}$, respectively, which are comparable to the state-of-the-art nonprecious catalyst and commercial $\mathrm{Pt} / \mathrm{C}$. ORR catalysis on MOF-FeZn follows the nearly fourelectron path. What is more, MOF-FeZn can sustain the 10,000 cycles electrochemical potential cycling process in acid with the half-wave potential changed only $21 \mathrm{mV}$, superior to the reduction of $149 \mathrm{mV}$ for Pt/C. The well-developed integral uniform structures, homogeneously dispersed carbides and nitrides protected by the highly graphitic carbon layers and the better agglomeration suppression of nanoparticles by the confined graphitic carbon layers on catalyst can significantly enhance the catalytic activity and stability of MOF-FeZn.
\end{abstract}

Handling Editor: Mark Bissett.

Address correspondence to E-mail: wangcheng@tsinghua.edu.cn 


\section{Introduction}

As one of the most efficient energy conversion devices, proton exchange membrane fuel cell shows great potentials in the application of hydrogen vehicles, stationary power plants and renewable energy utility [1]. Being a vital bottleneck in achieving the largescale application of fuel cells, cathodic ORR catalysts with higher activity and durability have been extensively explored and investigated to facilitate the sluggish ORR process [2]. Normally, precious platinum and its alloys are popularly used to accelerate the ORR catalysis. However, the high price, scarity of resources and limited stability of Pt-based catalysts have held back the commercialization [3]. Great attention has been paid to investigate and develop the highly active nonprecious metal or metal-free ORR catalysts [4]. Modification of carbon materials varies from doping the heteroatoms of $\mathrm{N}, \mathrm{P}, \mathrm{S}, \mathrm{B}, \mathrm{F}$, etc., incorporating with carbon and creating topological defects on them, to developing the atomically metal induced defective carbons with metal-macrocycle complexes, which are all effective methods to enhance the catalytic activity of carbon catalysts [5-9].

Modified carbon materials, such as carbon nanotubes, graphene and mesoporous carbons with unique physical and chemical properties after doping with heteroatoms, have drawn intensive interest for their excellent performances in ORR catalysis [10-13]. Among the generally doped foreign atoms, nitrogen could not only alter the electronic property and crystal structure of catalysts, but also prominently transform the chemical stability, surface polarity and electron-donor properties of the carbon materials, which effectively promoted the ORR catalysis [14]. Nitrogen type in the catalyst modification is one of the most fatal factors for ORR catalysis. Usually, several typical nitrogen structures are believed to be catalytic active for ORR catalysis, namely pyridinic $\mathrm{N}$, pyrrolic $\mathrm{N}$, quaternary $\mathrm{N}$ and pyridine- $\mathrm{N}$-oxide [15]. Electronegativity is another key factor to affect the catalytic property of carbon by influencing the surface charge density, which benefits the ORR process through facilitating the formation of oxygen adsorption sites on the modified carbon atoms [1,4].

Fabrication of effective nonprecious ORR catalysts with earth-abundant metals have been paid much more attention [16, 17]. A lot of pioneering work have been done by Dai and co-workers [18] on ORR catalysis with the modified CNTs. They proved that the generation of positive charges on the surrounding modified $\mathrm{C}$ atoms with incorporated high electronegative $\mathrm{N}$ atoms was catalytic active for ORR [19-21]. Sun and Lai et al. [22-24] demonstrated that both the pyridinic $\mathrm{N}$ and graphitic $\mathrm{N}$ were beneficial for ORR catalysis. Quaternary nitrogen (graphitic N), located at the edge of graphene planes, is more active for ORR, because the enriched carbon defects on edges facilitate the incorporation of nitrogen and activation of carbon [1,25]. N-modified graphene can exhibit improved ORR activity, demonstrating the crucial role of nitrogen in creating defective active sites by interrupting the original state of graphene $[26,27]$. Lai et al.[23] proved that it was the graphitic $\mathrm{N}$ in modified graphene that showed the higher limiting current density in catalysis, and pyridinic $\mathrm{N}$ was more beneficial to elevating the ORR onset potentials. Niu et al. [28, 29] demonstrated that mesopores at around $2-50 \mathrm{~nm}$ could remarkably contribute to enhancing the mass transportation of relevant electrochemical species, and prominently facilitating the ORR catalysis. The high specific surface area, abundant mesoporous architecture and well-modified nitrogen structure can render the mesoporous carbon materials to the excellent ORR catalysts. Atomic-dispersive metal species are also capable of modulating the electronic structure and configuration of carbon catalysts, producing defective carbon active sites with improved catalytic activity. Most of the metal-nitrogen-based catalysts show excellent ORR activity and durability in alkaline electrolytes. However, only a few works reported the comparable activities in acidic electrolytes [30-32], because transitional metals in the nonprecious catalysts are liable to be dissolved in acidic electrolytes and aggregate under fuel cell operating conditions, suffering severe damage and serious losses during the potential cycling processes. Therefore, developing the stable and catalytic active nonprecious ORR catalyst remains to be a meaningful and challenge work.

Herein, this article illustrates a preparation of an ultra-dispersive Fe- and Zn-doped nonprecious MOF catalyst with a combined hydrothermal crystallization and pyrolysis processes. With the integral uniform catalytic active structures developed both on the surface and in the bulk, this catalyst displays good 
ORR catalytic activity and prominent stability in $\mathrm{HClO}_{4}$.

\section{Experiment}

\section{Materials}

This iron-based integral uniform macrocyclic organic framework catalyst (MOF-FeZn) was prepared with a group of materials listed below, which were easily access and relatively simple. Iron (III) chloride $\left(\mathrm{FeCl}_{3}\right.$, $\mathrm{CP})$, urea $\left(\mathrm{CH}_{4} \mathrm{~N}_{2} \mathrm{O}, \mathrm{AR}\right)$, polyethylene-polypropylene glycol (F127, $\mathrm{Mn} \sim 13,000)$, imidazole $\left(\mathrm{C}_{3} \mathrm{H}_{4} \mathrm{~N}_{2}\right.$, AR), tannic acid $\left(\mathrm{C}_{76} \mathrm{H}_{52} \mathrm{O}_{46}, A R\right)$ and zinc chloride $\left(\mathrm{ZnCl}_{2}, \mathrm{AR}\right)$ were all commercial products purchased from Shanghai Macklin Biochemical Co., Ltd. All chemicals are well to use without further purification.

\section{Synthesis of the super uniform MOF-FeZn}

Typically, this catalyst was prepared as follows:

Firstly, $0.5 \mathrm{~g}$ surfactant F127 was fully dissolved into $40 \mathrm{~mL}$ deionized water in a sealed three-neck flask, which was stirred and heated in an oil-bath pot under $105{ }^{\circ} \mathrm{C}$. Then, $1.5 \mathrm{~g}$ tannic acid, $1 \mathrm{~g}$ imidazole and $1 \mathrm{~g}$ urea were added into the flask one after another. Some water was added to clean the bottle neck. The color of the mixture was milk-white at first. After continuously stirring under $105^{\circ} \mathrm{C}$, the color turned into clear dark yellow. At this time, took $20 \mathrm{~mL} 0.1 \mathrm{M} \mathrm{FeCl}_{3}$ aqueous solution and added it into the mixture. The solution transformed to dark blue black immediately. Complexation and chelate reactions among the added components were proceeded under $105{ }^{\circ} \mathrm{C}$ for $60 \mathrm{~min}$. After that, $1.32 \mathrm{~g}$ $\mathrm{ZnCl}_{2}$ was dissolved and put into the combined compounds to better connect and dispersive distribute among the organic precursors. Afterward, the suspentions were reacted and incorporated under stirring for another $6 \mathrm{~h}$. Then, the color transferred to brawn black finally. This obtained mixed solution went through hydrothermal-static crystallization in a high-pressure reaction kettle for another $48 \mathrm{~h}$ under $105{ }^{\circ} \mathrm{C}$. The generated precipitation was collected by centrifugation and desiccation. After drying under 60 ${ }^{\circ} \mathrm{C}$ sufficiently, the obtained powder was ultimately paralyzed under $800{ }^{\circ} \mathrm{C}$ for $2 \mathrm{~h}$ in $\mathrm{N}_{2}$ atmosphere to experience the final carbonization and pore construction. The ramping rate of calcination was 5 ${ }^{\circ} \mathrm{C} \min ^{-1}$.

\section{Characterization techniques}

Physical properties of MOF-FeZn catalyst were investigated by the following characterization techniques. Transmission electron microscope (TEM) images were performed on the JEM-1200EX (JEOL, Tokyo, Japan) with an acceleration voltage of $120 \mathrm{kV}$. High-resolution TEM (HRTEM), EDS and high-angle annular dark field (HAADF)-STEM images were examined by the JEM-2100F (JEOL, Tokyo, Japan) under $200 \mathrm{kV}$ with the EDS type of XFLASH5030 (Brucker). X-ray diffraction (XRD) analysis was carried out on BRUCKER D8 ADVANCE instrument with Co $(\mathrm{K} \alpha, \lambda=0.179 \mathrm{~nm})$ radiation, due to the magnetic property of catalysts. Raman spectra were conducted on a spectrometer of Renishaw inVia with a $532 \mathrm{~nm}$ laser on. X-ray photoelectron spectrometer (XPS) spectra were tested on an imaging photoelectron spectrometer of Thermo ESCALab 250XI instrument (Thermo Scientific, USA) with a monochromatic Al $\mathrm{K} \alpha$ X-ray source (hv = $1486.6 \mathrm{eV}$; charged correction in the spectra: $284.8 \mathrm{eV}$ ). The BET measurements were recorded on a Micromeritics ASAP2460 instrument (Micromeritics, Norcross, GA, USA) with nitrogen adsorption apparatus at $77 \mathrm{~K}$. ICP-OES was determined by Agilent ICPOES730 with the RF power of $1 \mathrm{~kW}$ and carrier gas of Ar.

\section{Electrochemical measurements}

Electrochemical measurements were performed on Reference $3000^{\mathrm{TM}}$ (Gamry, USA) electrochemical workstation in a typical three-electrode system with saturated calomel electrode (SCE) used as the reference electrode. The working electrode, prepared by catalyst ink drop-casting method on a glassy carbon electrode (GCE, $\mathrm{d}=4 \mathrm{~mm}$ ), was obtained following typical procedures. The drop-casting ink was prepared by adding $5 \mathrm{mg}$ MOF-FeZn catalyst and $50 \mu \mathrm{L}$ Nafion (DuPont Corp., 5\%) to $1 \mathrm{~mL}$ isopropyl alcohol, sonicating with ultrasound for more than $30 \mathrm{~min}$ to sufficiently disperse. After homogeneous dispersion, $10 \mu \mathrm{L}$ mixture was evenly coated onto the polished GCE progressively to form a catalyst film. The MOF-FeZn catalyst loading was $0.379 \mathrm{mg} \mathrm{cm}^{-2}$ in all the tests. For better comparison, commercial $\mathrm{Pt} / \mathrm{C}$ (JM, 40\%) was used to prepare the comparing 
working electrode. The acidic electrolyte in our test is $0.1 \mathrm{M} \mathrm{HClO}_{4}$. All potentials are adjusted relative to the typical RHE according to the conversion formula below:

$E_{\mathrm{RHE}}=E_{\mathrm{SCE}}+0.0591 \mathrm{pH}+0.2412$

\section{Results and discussion}

Integral uniform MOF-FeZn catalyst was typically synthesized through the hydrothermal and pyrolysis processes. The added organic materials went through the hydrogen-bond interaction and dehydration condensation reactions with particular functional groups, forming tight conjunction organic skeletons by stacking and covalent bonds [22, 33]. After chelating and complexation with metal ions, integral uniform precursors were obtained. Going through the hydrothermal crystallization, these organic skeletons were well developed and sufficiently interacted. Finally, the collected powder underwent carbonization to form the active components, developing porous structures at the same time.

Morphology characteristics of MOF-FeZn were identified by TEM and HRTEM (Fig. 1). In the low magnification images, we can see that this catalyst is a straticulate folded graphene structure, which is similar to the rime ice flowers (Fig. 1a and b). As shown in the high magnification images, well-distributed metal granules dispersively inlayed in the carbon matrixes (Fig. 1c-f). In Fig. 1d and e, there are many fish scaly structures formed with intensively scattered or tactic distributed metal carbide nanoparticles for the confined carbon lattices. Because of the well-proportioned organic skeletons as well as the good combination and interaction of metal ions, this catalyst develops into an integral uniform structure, which is not only catalytic active on the surface, but also highly active in the matrix. This is very important for MOF-FeZn to provide persistent activity and longer durability in electrochemical catalysis. Moreover, the well contact of nanoparticles and graphitic layers are also meaningful to improving the activity and stability of catalyst. However, there are few well-constructed crystal texture metallic carbides formed in the matrix as shown in (Fig. $1 \mathrm{~g}$ and $h$ ). The clear crystal lattice fringes demonstrate the good crystallization of carbon and metal carbides with the interfringe distances of $0.2075 \mathrm{~nm}$ and
$0.348 \mathrm{~nm}$ in and out the particles, which are correspondingly belonging to the lattice spacing of (021) plane of for $\mathrm{Fe}_{5} \mathrm{C}_{2}$ and (002) plane for graphitic carbon, respectively. The lattices of $\sim 0.21 \mathrm{~nm}$ are consistent with the (211) plane of $\mathrm{Fe}_{3} \mathrm{C}$, further demonstrating the well-developed metallic carbide crystal textures. The enlarged carbon interlayer distances $(>0.34 \mathrm{~nm})$ are owing to the heteroadulteration of $\mathrm{Fe}, \mathrm{Zn}$ and $\mathrm{N}$ substances in carbon. These encapsulated nanoparticles are believed to activate the graphitic layers, making positive contributions to catalysis.

Elemental mapping and electron diffraction properties of the prepared MOF-FeZn catalyst were characterized with the HAADF-STEM (Fig. 2). Comprehensively, this catalyst is an integral uniform Fe-, Zn-, N-modified catalyst with numerous dispersive tiny nanoparticles inlayed among graphitic carbon lattices. Its element distribution, revealed by the above EDS mappings, demonstrates the well distribution and good combination of $\mathrm{C}, \mathrm{O}, \mathrm{N}, \mathrm{Fe}$ and $\mathrm{Zn}$ (Fig. 2c-f, h-i). The relevant dispersive SAED diffraction pattern in Fig. $2 g$ further indicates the existence of well-crystalline metallic compounds.

Physical features and properties of MOF-FeZn were sufficiently characterized in Fig. 3. The XRD pattern matched well with the iron carbide and nitride structures (Fig. 3a). Specifically, the broad diffraction peak at around $26.9^{\circ}$ is associated with the graphite carbon, and the peaks at around $27.61^{\circ}$, $30.97^{\circ}, 41.31^{\circ}, 51.03^{\circ}, 53.26^{\circ}, 74.44^{\circ}$ and $83.78^{\circ}$ are ascribed to $\mathrm{Fe}_{3} \mathrm{C}$ (JCPDS no. 03-065-0393, 89-2876). The peaks at $52.40^{\circ}$ and $59.50^{\circ}$ are belonging to $\mathrm{Fe}_{5} \mathrm{C}_{2}$ (JCPDS no. 01-089-8968). The $52.40^{\circ}$ and $77.43^{\circ}$ peaks are assigned to the metallic Fe (JCPDS no. 01-0870721). The formation of $\mathrm{Fe}_{4} \mathrm{~N}$ substance can be proved by the $48.16^{\circ}$ and $89.27^{\circ}$ peaks (JCPDS no. 01-086-0231, 01-077-2006). As we can see, most of the doped metal ions in MOF-FeZn are developed into iron carbides and nitrides, further conforming the well combination of $\mathrm{Fe}-\mathrm{C}, \mathrm{N}$ (Fig. 2). The iron carbides or iron nitrides display relative weak diffraction peaks in XRD pattern, further confirming the tiny crystal or even amorphous structure of the doping substances, and some of which are not detectable through XRD. Raman spectrum was recorded to characterize and testify the graphitization property of MOF-FeZn (Fig. 3b). Accordingly, this catalyst has obviously high graphitic property with a typical $\mathrm{I}_{\mathrm{D}} / \mathrm{I}_{\mathrm{G}}$ ratio of 0.945 , indicating the ordered 
Figure 1 TEM and HRTEM characterization of MOFFeZn. a, b Low magnification images of MOF-FeZn; c-f High magnification images of MOF-FeZn; g, h High magnification images of metal carbide.

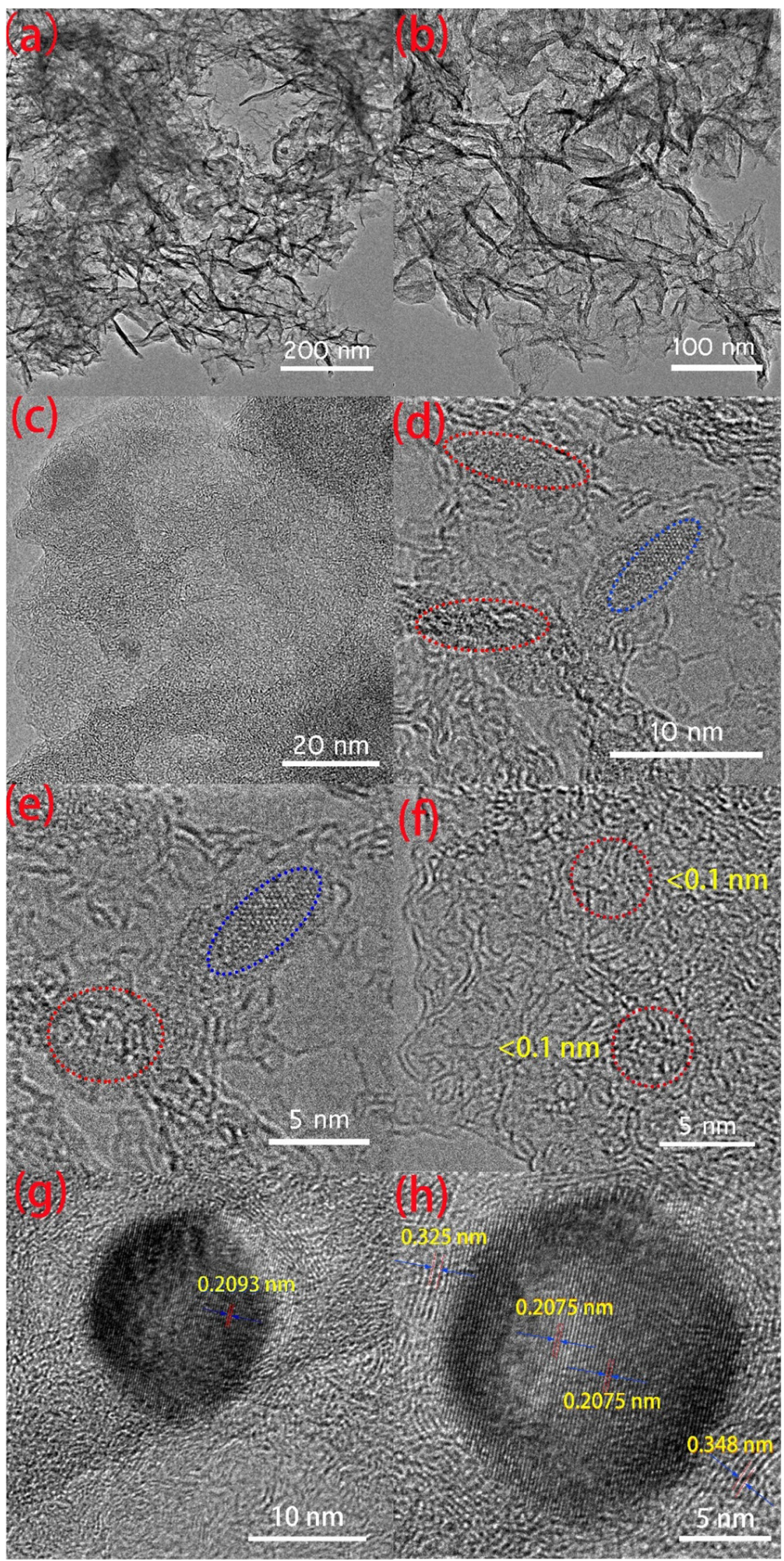




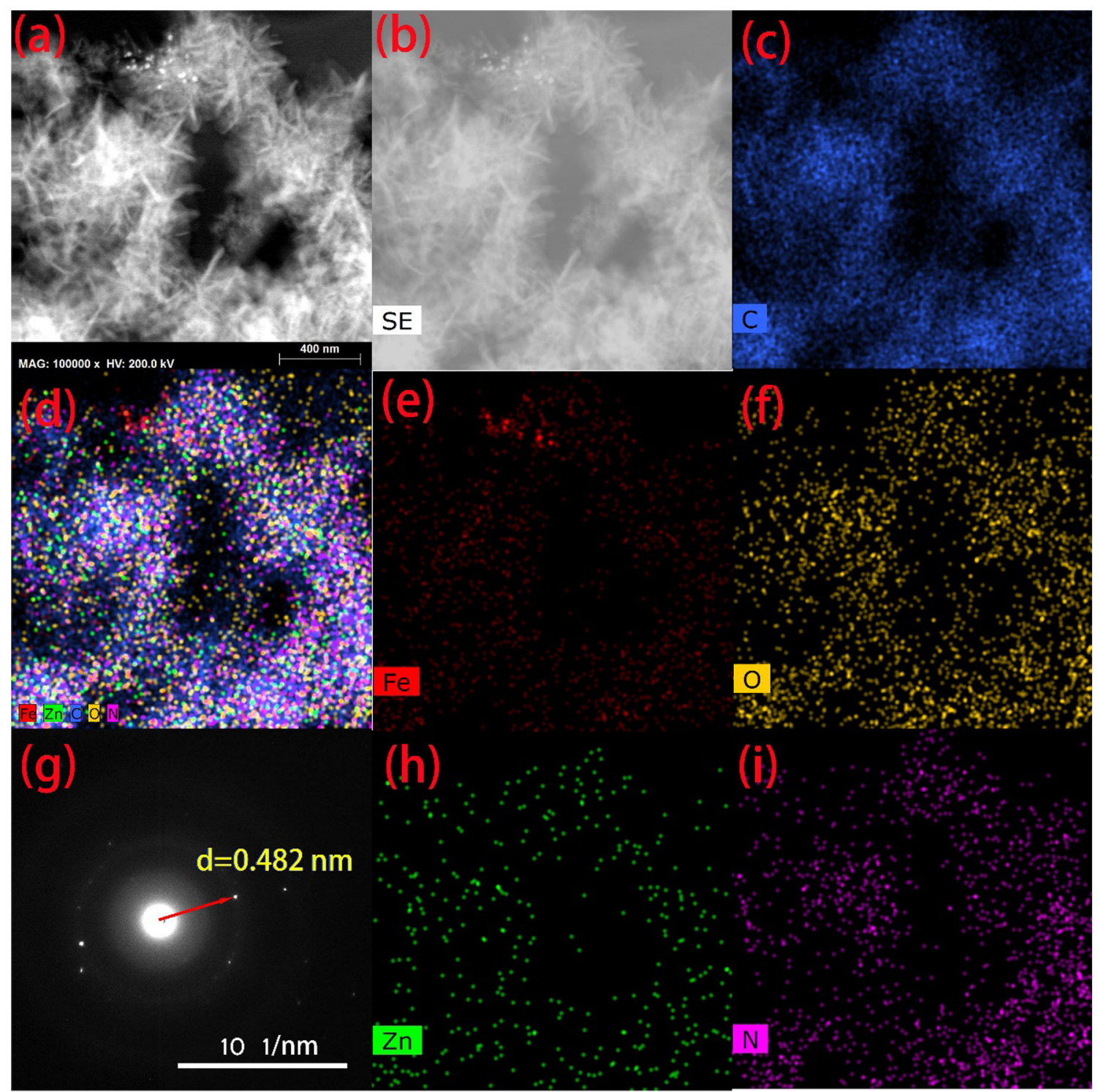

Figure 2 EDS and HAADF-STEM images of MOF-FeZn. a, b HAADF-STEM images of MOF-FeZn; c elemental mapping image of $\mathrm{C}$ for $\mathrm{MOF}-\mathrm{FeZn}$; $\mathbf{d}$ superimposed elemental mapping image of $\mathrm{C}, \mathrm{N}, \mathrm{O}, \mathrm{Fe}, \mathrm{Zn}$ for MOF-FeZn; e elemental mapping

graphitic carbon structure of MOF-FeZn due to the sufficient pyrolysis under $800{ }^{\circ} \mathrm{C}$ in $\mathrm{N}_{2}$. The intensive $\mathrm{D}$ band at around $1345.2 \mathrm{~cm}^{-1}$ implies the rich disordered defects in catalyst. Moreover, the noteworthy broad band 2D is from $2328 \mathrm{~cm}^{-1}$ to $3275 \mathrm{~cm}^{-1}$, demonstrating that the straticulate folded graphene is in multilayer structure. Numerous graphitic fringes and defects in catalyst will activate the ORR catalytic activity of MOF-FeZn [34-38]. As shown in Fig. 3c and $\mathrm{d}$, the $\mathrm{N}_{2}$ adsorption/desorption isotherm of MOF-FeZn belongs to the prominent type IV image of $\mathrm{Fe}$ for MOF-FeZn; f elemental mapping image of $\mathrm{O}$ for MOF-FeZn; $g$ SAED patterns of metallic carbide in MOF-FeZn; h elemental mapping image of $\mathrm{Zn}$ for MOF-FeZn; i elemental mapping image of $\mathrm{N}$ for MOF-FeZn.

isotherm with remarkable hysteresis loops, which indicate the mesoporous structure of catalyst. Porosity properties were assessed and analyzed by BET method. The catalyst surface area is up to 529.92 $\mathrm{m}^{2} \mathrm{~g}^{-1}$. Based on the BJH analysis, the total pore volume is $0.729 \mathrm{~cm}^{3} \mathrm{~g}^{-1}$, and the mesopore volume can be as many as $0.662 \mathrm{~cm}^{3} \mathrm{~g}^{-1}$. Some of the mesopores are intensively located at around $4 \mathrm{~nm}$ as shown in the insert graph in Fig. 3d. This typical pore size is significant for electrocatalysis [37-39]. Some pores are widely distributed from 10 to $50 \mathrm{~nm}$, which 

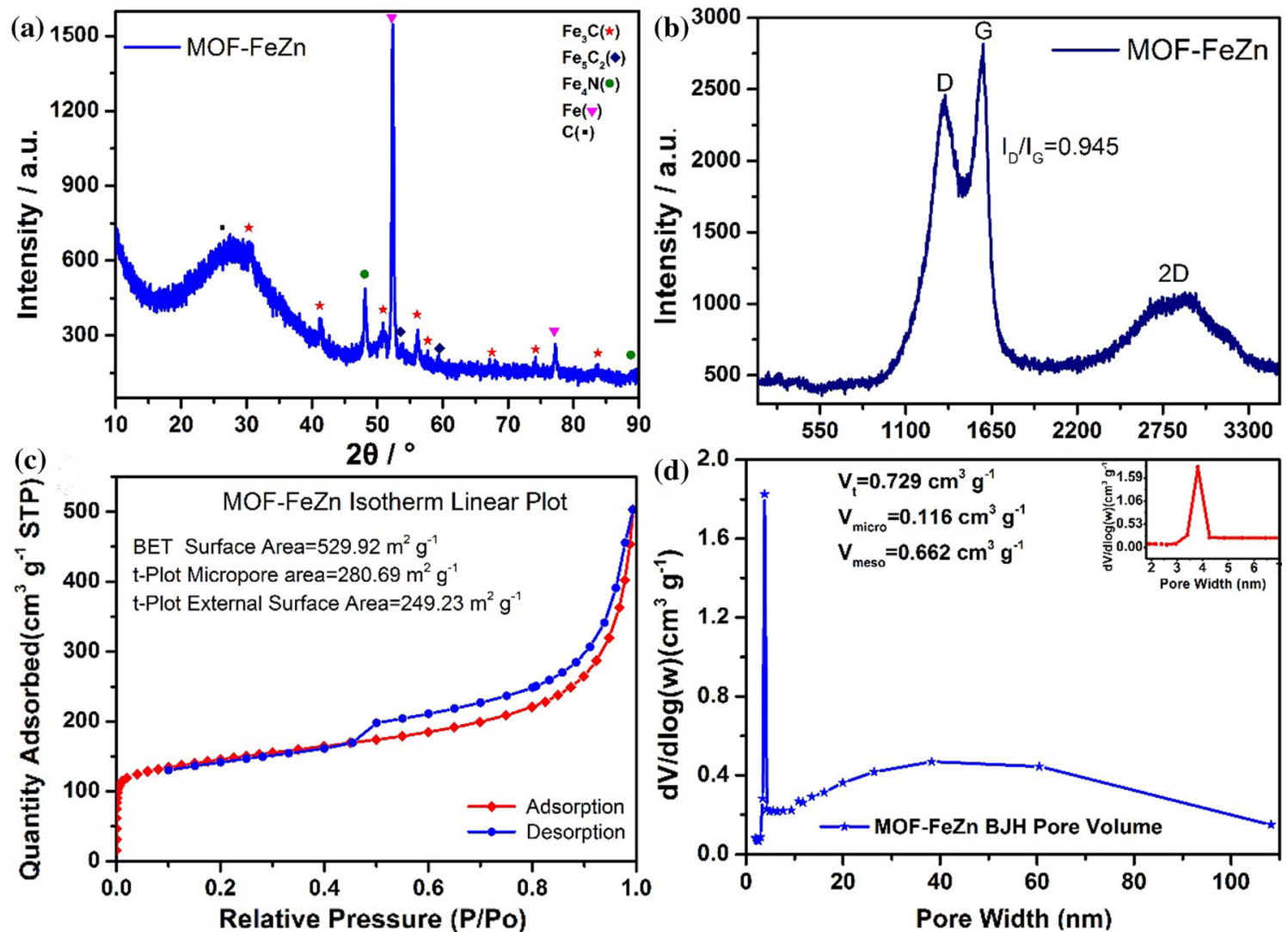

Figure 3 Physical characterizations of MOF-FeZn catalyst. a XRD pattern (b) Raman spectra (c) BET adsorption and desorption isotherm (d) pore distribution.

are beneficial for the rapid transportation of reactant species. In brief, this catalyst exhibits high surface area, desired mesoporous structures and large pore volume, which are all favorable for active site exposure and reactants transport $[38,40]$.

The exact mass contents of $\mathrm{Fe}$ and $\mathrm{Zn}$ in MOFFeZn catalyst were analyzed to be 33.92 wt. $\%$ and $1.05 \mathrm{wt} . \%$, respectively, using the ICP-OES technique. This content is very different from the initial addition of $\mathrm{Fe}$ and $\mathrm{Zn}\left(\mathrm{n}_{\mathrm{Fe}}: \mathrm{n}_{\mathrm{Zn}}=1: 4.84, \mathrm{~mol} / \mathrm{mol}\right)$. Because $\mathrm{ZnCl}_{2}$ is easily evaporated under $800{ }^{\circ} \mathrm{C}$ during pyrolysis, demonstrating the existence of $\mathrm{Zn}$ in precursor is $\mathrm{Zn}^{2+}$ instead of the metal (boiling point of metallic $\mathrm{Zn}$ is $\left.907^{\circ} \mathrm{C}\right)$. $\mathrm{ZnCl}_{2}$ in precursor, acting as the pore-creating agent, is mainly sacrificed in the carbonization. Moreover, specific surface element contents were characterized by XPS, which were conducted to elucidate the composition and bonding configuration of different elements on the surface of MOF-FeZn (Fig. 4). Generally, this catalyst is composed of C (86.81 at.\%), O (7.57 at.\%), N (4.67 at.\%), Fe $(0.67$ at. $\%)$ and $\mathrm{Zn}(0.27$ at.\%) on the surface, demonstrating the successful doping of heteroatoms. Compared to the ICP analysis, we can see most of the doping metals are encapsulated deep in the carbon matrix with abundant active sites developed both in the matrix and out on the surface of MOF-FeZn. For C $1 \mathrm{~s}$ spectra, the intensive sp2 C peak, centered at $284.6 \mathrm{eV}$ (Fig. 4a), implies the high graphitization of MOF-FeZn coincident to the Raman analysis, enhancing the catalytic activity by increasing the electrical conductivity [41]. According to the O1s spectra (Fig. 4b), oxygen content in this catalyst is relatively high, because of the formation of oxygenrich functional groups in organics. Certain amount of $\mathrm{C}-\mathrm{O}$ and $\mathrm{C}=\mathrm{O}$ groups enhance the transport of electrolytes, benefiting the interaction between catalysts and electrolytes. The deconvoluted N 1 s spectrum is composed of five peaks, assigning to pyridinic N, Fe$\mathrm{N}$, pyrrolic $\mathrm{N}$, graphitic $\mathrm{N}$ and oxidized $\mathrm{N}$, respectively (Fig. 4c), most of which are recognized as active components except for the small amount oxidized N. Particularly, the deconvolution peaks clearly indicate the high ratio of Pyridinic $\mathrm{N}$ and 

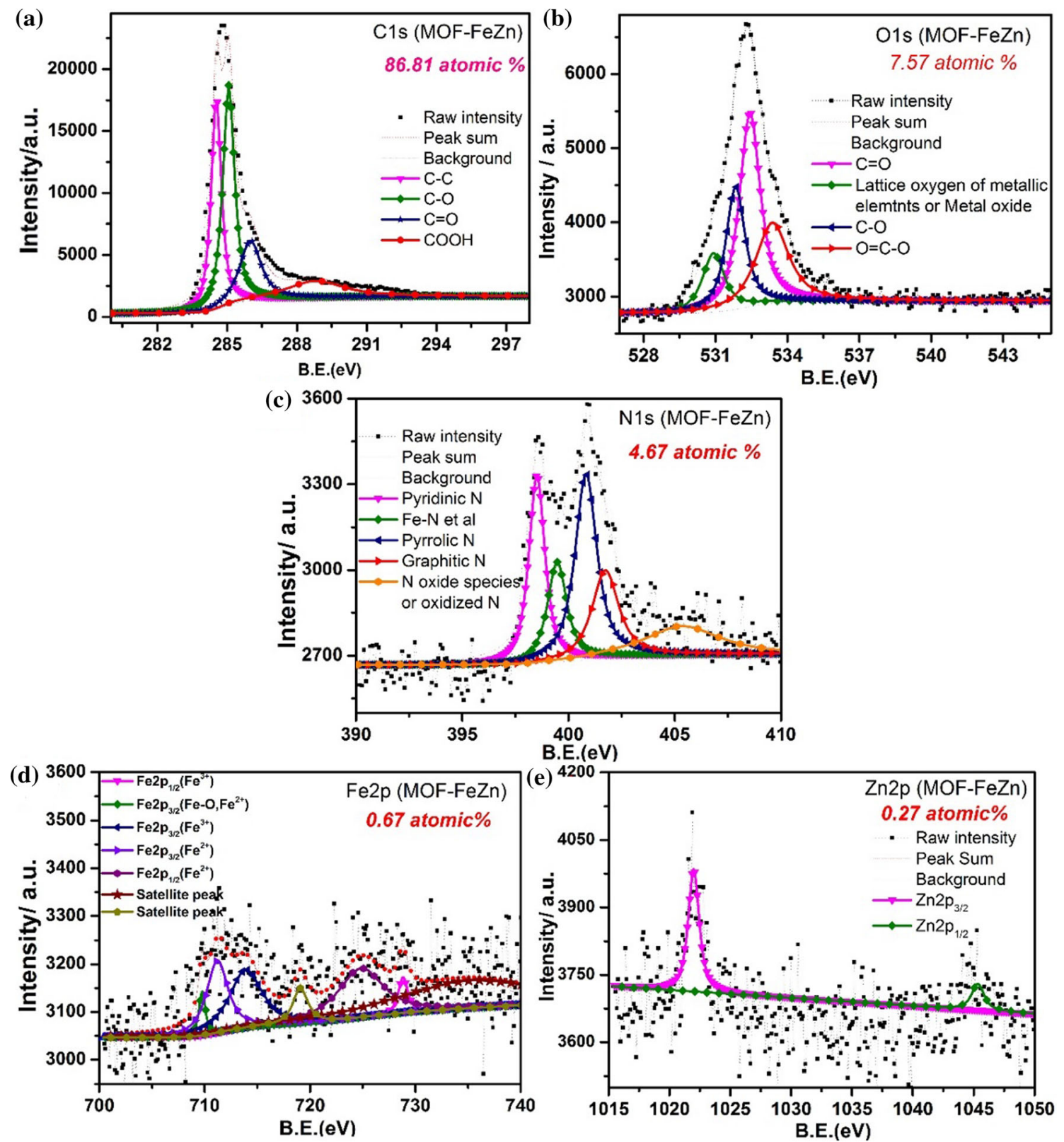

Figure 4 High-resolution XPS spectra. a C1s, b O1s, c N 1 s, d Fe2p, e Zn2p.

pyrrolic $\mathrm{N}$ with relatively rich $\mathrm{Fe}-\mathrm{N}$ and graphitic $\mathrm{N}$ in this catalyst, implying the rich active sites formed. The deconvolution peak of $\mathrm{Fe} 2 \mathrm{p}$ reveals two pairs of doublets of the $\mathrm{Fe} 2 \mathrm{p}_{3 / 2}$ and $\mathrm{Fe} 2 \mathrm{p}_{1 / 2}$ peaks, demonstrating the combination state of $\mathrm{Fe}$ and further confirming the present of iron carbide and nitride species in catalyst at around $711.1 \mathrm{eV}$ and $724.6 \mathrm{eV}$ as well as at $713.7 \mathrm{eV}$ and $728.8 \mathrm{eV}$ with the satellite peak at $719.1 \mathrm{eV}$ (Fig. 4d). The content of $\mathrm{Zn}$ is very low and mostly in the ion state.
As shown above, this as-synthesized MOF-FeZn catalyst is a well-established nonprecious metal organic framework catalyst, on which the effective adulteration of $\mathrm{N}$, proper combined $\mathrm{Fe}-\mathrm{N}$, and the highly dispersive embedded metal carbides and nitrides, as well as the integral uniform distribution of active sites, display synergetic effects for catalysis. Meanwhile, the relatively high specific surface area, typical mesoporous features, unique pore sizes and large pore volumes are all beneficial for the improvement of catalyst activity, due to their great 
contribution to the development of active sites and fast transport of reactants.

Compared with the commercial $\mathrm{Pt} / \mathrm{C}$, this as-prepared integral uniform MOF-FeZn catalyst has noteworthy ORR activity and favorable stability in acidic electrolyte (Fig. 5), which are evaluated by the rotating disk electrode in $0.1 \mathrm{M} \mathrm{HClO}_{4}$. Linear sweep voltammetry curves (LSV; Fig. 5a) of MOF-FeZn clearly demonstrate the good ORR activity in acidic electrolyte with the onset potential ( $\left.\mathrm{E}_{\text {onset }}\right)$ of $0.93 \mathrm{~V} @$ $0.1 \mathrm{~mA} \mathrm{~cm}^{-2}$, the half-wave potential $\left(\mathrm{E}_{1 / 2}\right)$ of $0.768 \mathrm{~V} @ 2.757 \mathrm{~mA} \mathrm{~cm}^{-2}$ and the limited diffusion current density $\left(\mathrm{j}_{\mathrm{d}}\right)$ of $5.5 \mathrm{~mA} \mathrm{~cm}{ }^{-2}$, only slightly inferior to the commercial Pt/C $\left(\mathrm{E}_{\text {onset }}=0.959 \mathrm{~V} ; \mathrm{E}_{1}\right.$ / ${ }_{2}=0.833 \mathrm{~V} ; \mathrm{j}_{\mathrm{d}}=5.5 \mathrm{~mA} \mathrm{~cm}^{-2}$ ). The high ORR catalytic performance of MOF-FeZn can be ascribed to the good electrical conductivity, high specific surface area and well-developed mesoporous architecture
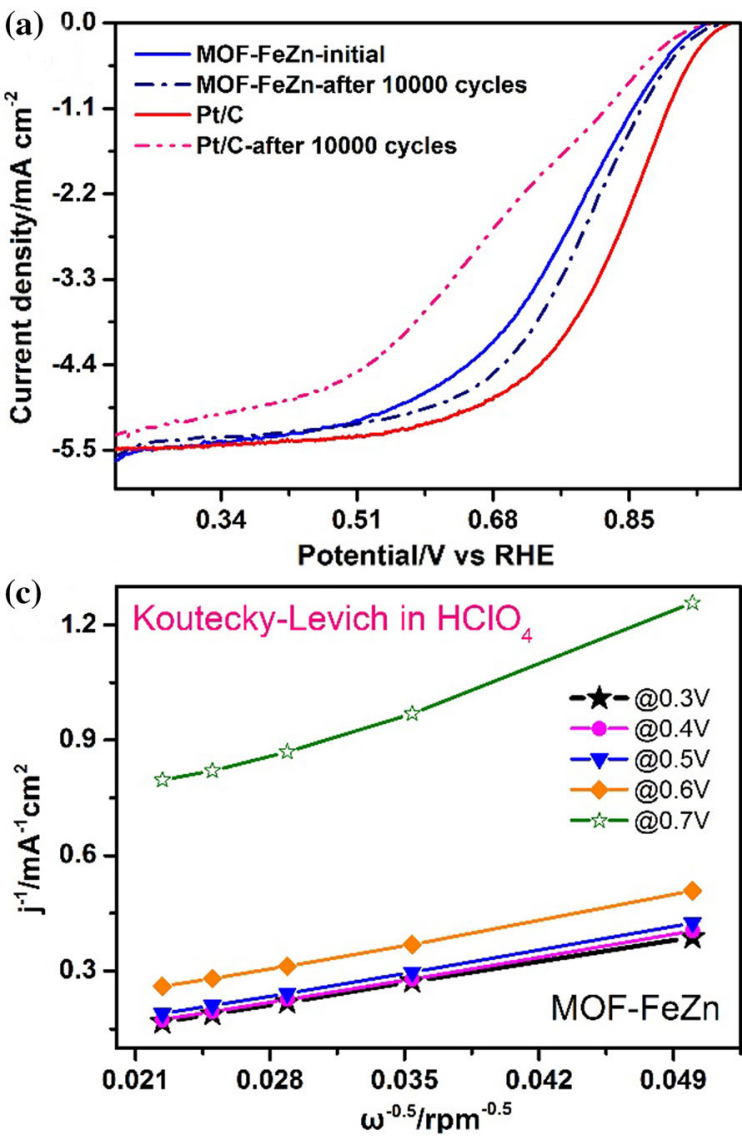

Figure 5 Electrochemical activities and stability of MOF-FeZn and Pt/C. a ORR curves before and after the ADT tests in $0.1 \mathrm{M}$ $\mathrm{HClO}_{4}$; LSV:1600 rpm, $\mathrm{O}_{2}$ saturated, $10 \mathrm{mV} \mathrm{s}{ }^{-1}$. b Cyclic voltammetry curves before and after the ADT tests in $0.1 \mathrm{M}$ $\mathrm{HClO}_{4}$; CV: $0.05 \sim 1.2 \mathrm{~V}, \mathrm{~N}_{2}$ saturated, $50 \mathrm{mV} \mathrm{s}^{-1}$. ADT tests: with the successful modified $\mathrm{N}$ and Fe substances. In Fig. 5b, cyclic voltammetry (CV) curves reveal the high specific surface area of MOF-FeZn with a large double electric layer capacitance, indicating the porous structure and good electrical conductivity of this catalyst. The long-term stability of MOF-FeZn and $\mathrm{Pt} / \mathrm{C}$ was compared, following the accelerated durability test (ADT) by cycling the potentials up to 10,000 times between 0.6 and $1.0 \mathrm{~V}$ in $\mathrm{N}_{2}$-saturated $\mathrm{HClO}_{4}$ under $100 \mathrm{mV} \mathrm{s}^{-1}$. CV and LSV tests were performed before and after the ADT protocols, respectively (Fig. 5a and b). After cycling in the wide potential range, MOF-FeZn still remains good electrochemical features as shown in Fig. $5 b$ with no special peaks appeared in the CV curves. The slightly enlarged double electronic layer of $\mathrm{CV}$ curve indicates the enhanced hydrophilia of MOF-FeZn catalyst during the ADT process, which is obviously
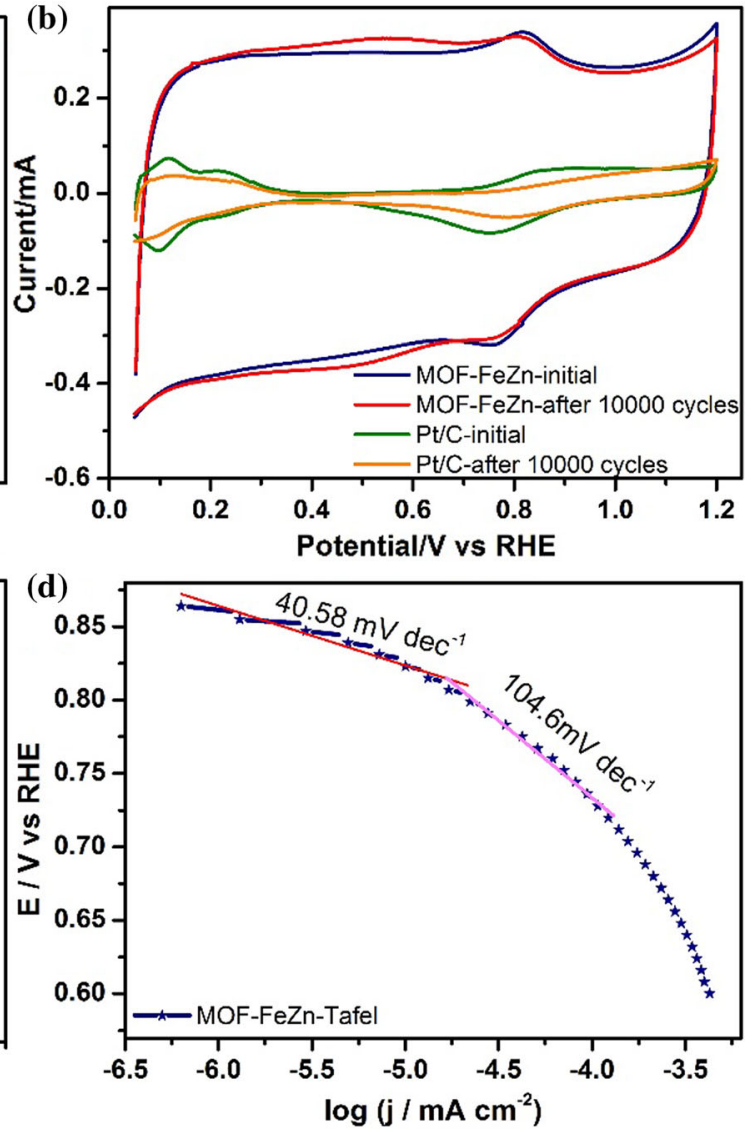

$0.1 \mathrm{M} \mathrm{HClO}_{4}, 100 \mathrm{mV} \mathrm{s}^{-1}, \mathrm{~N}_{2}, 0.6 \sim 1 \mathrm{~V}, \mathrm{CV}$ cycles. c The corresponding $\mathrm{K}-\mathrm{L}$ analysis of $\mathrm{MOF}-\mathrm{FeZn}$, based on the LSV curves under different rotation speeds in $0.1 \mathrm{M} \mathrm{HClO}_{4}\left(\mathrm{LSV}: \mathrm{O}_{2}\right.$ saturated, $10 \mathrm{mV} \mathrm{s}^{-1}$, rotation speeds: at 400, 800, 1200, 1600, $2000 \mathrm{rpm}$. d Tafel analysis of MOF-FeZn. 
different form the remarkable reduction of electrochemical active specific surface area of commercial $\mathrm{Pt} / \mathrm{C}$. The changed hydrophilia properties and adsorbed functional groups can change the adsorption and desorption of reactants, influencing the catalytic process. Foremostly, this nonprecious MOFFeZn catalyst well sustains the harsh electrochemical potential cycling process in acid with the half-wave potential only changed $21 \mathrm{mV}$, superior to the reduction of $149 \mathrm{mV}$ for $\mathrm{Pt} / \mathrm{C}$. The limited diffusion current of MOF-FeZn is also relatively stable than $\mathrm{Pt} / \mathrm{C}$ (Fig. 5a). The remarkably stable ORR activity after 10,000 potential cycles in a wide oxidation potential range can be ascribed to the ultra-dispersive integrative structure and high graphization of MOF$\mathrm{FeZn}$, preventing the active sites from serious destroyed. The less prominent ORR activity attenuation on MOF-FeZn after the potential cycles is because this catalyst displays an integral uniform structure with abundant active sites not only on the surface but also in the bulk matrix of the catalyst, so the $\mathrm{CV}$ curve before and after ADT is similar and the half-wave potentials are close. However, the $\mathrm{Pt} / \mathrm{C}$ underwent significant decrease in the ADT process with more obviously negative shifted half-wave potentials and significantly reduced limited diffusion current density. In brief, the results prove that this integral uniform MOF-FeZn catalyst has greatly improved ORR activity and favorable durability in acid with its homogeneously dispersive metal carbides and nitrides protected by high graphitic carbon layers. To further recognize the kinetic property of electrocatalysts, transferred electrons of MOF-FeZn were calculated based on the LSV curves under different rotation speeds in $\mathrm{O}_{2}$-saturated $\mathrm{HClO}_{4}$. The rotation speed of RDE was adjusted from 400 to $2000 \mathrm{rpm}$ with continuous flowing of $\mathrm{O}_{2}$ bubbles during the test. Koutecky-Levich (K-L) equation is applied to analyze the kinetic activity and transferred electrons of MOF-FeZn (Fig. 5c). The number of transferred electrons was calculated based on:

$j^{-1}=j_{L}^{-1}+j_{K}^{-1}=B^{-1} \omega^{-1 / 2}+j_{K}^{-1}$

$B=0.2 n \mathrm{FC}_{0} D_{0}^{2 / 3} v^{-1 / 6}$

where $\omega$ is the rotating speed in rpm. $j$ is the measured current density; $\mathrm{j}_{\mathrm{K}}$ and $\mathrm{j}_{\mathrm{L}}$ are the kinetic and limited diffusion current densities, respectively; $n$ is the number of transferred electrons; $\mathrm{F}$ is the Faraday constant (96 $485 \mathrm{C} \mathrm{mol}^{-1}$ ); $\mathrm{C}_{0}$ is the bulk concentration of $\mathrm{O}_{2}\left(1.2 \times 10^{-6} \mathrm{~mol} \mathrm{~cm}{ }^{-3}\right) ; \mathrm{D}_{0}$ is the diffusion coefficient of $\mathrm{O}_{2}\left(1.93 \times 10^{-5} \mathrm{~cm}^{2} \mathrm{~s}^{-1}\right)$; and $v$ is the kinematic viscosity of electrolyte $\left(0.01 \mathrm{~cm}^{2} \mathrm{~s}^{-1}\right)$. The corresponding $\mathrm{K}-\mathrm{L}$ plots show the relatively good linearity (Fig. 5c). B derived from the slope of $\mathrm{K}-\mathrm{L}$ plot of MOF-FeZn is 0.125 . Accordingly, the number of transferred electrons ( $\mathrm{n}$ ) is calculated to be 3.82 in $0.1 \mathrm{M} \mathrm{HClO}_{4}$ on MOF-FeZn, which is close to the ideal four-electron pathway of $\mathrm{Pt} / \mathrm{C}$ for oxygen reduction in acid, revealing relative fast ORR kinetic process on MOF-FeZn. Furthermore, Tafel analysis was also performed on MOF-FeZn in $0.1 \mathrm{M} \mathrm{HClO}_{4}$ (Fig. 5d). There is an obvious change at around $0.81 \mathrm{~V}$, above which the Tafel slop is $40.58 \mathrm{mV} \mathrm{dec}^{-1}$, and below which it transforms to $104.6 \mathrm{mV} \mathrm{dec}^{-1}$, revealing the relative fast kinetic process and significant change of kinetic activity in this region.

According to the above analysis, MOF-FeZn, an integral uniform nonprecious catalyst, exhibits good ORR catalytic activity and favorable stability in $\mathrm{HClO}_{4}$, which may be ascribed to the integral uniform structure of MOF-FeZn with sufficient active sites not only on the surface but also deep in the bulk parts, so the catalyst can still display excellent ORR activity after the potential cycling processes.

Comparing to the reported state-of-the-art nonprecious catalysts (Table 1), the preparation processes of MOF-FeZn are relative simple and easy to mass production. The raw materials for MOF-FeZn synthesis are relatively low toxicity and easily access, and the solvent used is just water. The catalysis of oxygen reduction on MOF-FeZn follows nearly fourelectron process, and the half-wave potential is slightly higher than the reported first-class nonprecious-metal catalysts. The stability of MOF-FeZn is among the best platinum-free catalysts in acid electrolyte. In a word, with the mild preparation method, MOF-FeZn catalyst develops into an integral uniform structure with highly dispersive active sites not only on the surface but also in the bulk, displaying good ORR catalytic activity and excellent stability in acid.

\section{Conclusion}

In summary, this as-synthesized integral uniform MOF-FeZn catalyst is a promising ORR candidate catalyst in acid. The high surface area and well-distributed nanoparticles inlayed in the $\mathrm{N}$-modified 
Table 1 Performances of the state-of-the-art nonprecious ORR catalysts

\begin{tabular}{|c|c|c|c|c|c|c|}
\hline No & Name & Category & Activity stability & Electrolyte & Methods & Literature \\
\hline 1 & $\begin{array}{l}\text { Defect-rich } \\
\text { carbon } \\
\text { spheres }\end{array}$ & $\begin{array}{l}\text { Metal-free } \\
\text { electrocatalyst }\end{array}$ & $\begin{array}{l}\mathrm{J}_{\mathrm{D}}=4.17 \mathrm{~mA} \mathrm{~cm}{ }^{-2} \\
13,500 \text { potential cycles }\end{array}$ & $\begin{array}{r}0.1 \mathrm{M} \\
\mathrm{KOH}\end{array}$ & $\begin{array}{l}\text { Solvothermal } \\
\text { carbonization of ethanol }\end{array}$ & {$[42]$} \\
\hline 2 & $\begin{array}{l}\text { Single-atom } \\
\text { Fe/N-doped } \\
\text { Porous carbon }\end{array}$ & $\begin{array}{l}\text { N-doped porous } \\
\text { carbon }\end{array}$ & $\begin{array}{l}\text { Outperformed commercial } \mathrm{Pt} / \mathrm{C} \text { and } \\
\text { most nonprecious-metal catalysts; } \\
5000 \text { Cycles; } \mathrm{E}_{1 / 2} \text { very little changed }\end{array}$ & $\begin{array}{r}0.1 \mathrm{M} \\
\mathrm{KOH}\end{array}$ & $\begin{array}{l}\text { A cage-encapsulated- } \\
\text { precursor pyrolysis } \\
\text { strategy }\end{array}$ & {$[43]$} \\
\hline 3 & $\begin{array}{l}\mathrm{Fe}-\mathrm{N} / \mathrm{C} \\
\text { Carbon } \\
\text { Nanotubes }\end{array}$ & $\begin{array}{l}\text { Single atomic } \mathrm{Fe}-\mathrm{N}_{4} \\
\text { active site catalyst }\end{array}$ & $\begin{array}{l}\mathrm{E}_{1 / 2}=0.736 \mathrm{~V} \\
0.9 \sim 1.4 \mathrm{~V}, 500 \text { cycles }\end{array}$ & $\begin{array}{l}0.1 \mathrm{M} \\
\mathrm{HClO}_{4}\end{array}$ & $\begin{array}{l}\text { Repeat carbonization and } \\
\text { leaching }\end{array}$ & {$[44]$} \\
\hline 4 & MOF-FeZn & $\begin{array}{l}\text { N-doping, } \mathrm{FeN}_{\mathrm{x}} \text { and } \\
\mathrm{ZnN}_{\mathrm{x}}\end{array}$ & $\begin{array}{l}0.93 \mathrm{~V} @ 0.1 \mathrm{~mA} \mathrm{~cm}{ }^{-2}, 0.768 \mathrm{~V} @ \\
2.757 \mathrm{~mA} \mathrm{~cm}\end{array}$ & $\begin{array}{l}0.1 \mathrm{M} \\
\mathrm{HClO}_{4}\end{array}$ & $\begin{array}{l}\text { High-temperature } \\
\text { pyrolysis }\end{array}$ & $\begin{array}{l}\text { This } \\
\text { work }\end{array}$ \\
\hline
\end{tabular}

carbon matrix provide sufficient active sites not only on the surface but also deep in the bulk. The wellexposed high contents of pyridinic $\mathrm{N}, \mathrm{Fe}-\mathrm{N}$, pyrrolic $\mathrm{N}$, graphitic $\mathrm{N}$ active sites and porous skeleton structures facilitate the mass-transfer and kinetic property in the ORR catalysis. Due to the synergetic contribution of the catalyst composition and structure, MOF-FeZn follows a nearly four-electron path in ORR catalysis with high limited diffusion current and half-wave potentials in $0.1 \mathrm{M} \mathrm{HClO}_{4}$. This integral uniform catalyst also displays favorable durability in acid for its homogeneously dispersive metal carbides and nitrides protected by high graphitic carbon layers both on the surface but also in the matrix.

\section{Acknowledgement}

The work was financially supported by the ChinaJapan Key Science and Technology Cooperation Program [No. 2018YFE0202003]; the National Key Research and Development Program of China [No. 2016YFB01 01208]; the National Natural Science Foundation of China [No. 21573122, No. 21773136]; Beijing Key Research and Development Program [No. Z18 1100004518004].

\section{Compliance with ethical standards}

Conflict of interest The author declares that they have no conflict of interest.

Open Access This article is licensed under a Creative Commons Attribution 4.0 International License, which permits use, sharing, adaptation, distribution and reproduction in any medium or format, as long as you give appropriate credit to the original author(s) and the source, provide a link to the Creative Commons licence, and indicate if changes were made. The images or other third party material in this article are included in the article's Creative Commons licence, unless indicated otherwise in a credit line to the material. If material is not included in the article's Creative Commons licence and your intended use is not permitted by statutory regulation or exceeds the permitted use, you will need to obtain permission directly from the copyright holder. To view a copy of this licence, visit http://creativecommons.org/licen ses/by $/ 4.0 /$.

\section{References}

[1] Yan X, Jia Y, Yao X (2018) Defects on carbons for electrocatalytic oxygen reduction. Chem Soc Rev 47:7628-7658

[2] Wang M-Q, Ye C, Wang M, Li T-H, Yu Y-N, Bao S-J (2018) Synthesis of $\mathrm{M}$ ( $\mathrm{Fe} 3 \mathrm{C} \mathrm{Co}, \mathrm{Ni})$-porous carbon frameworks as high-efficient ORR catalysts. Energy Storage Mater 11:112-117

[3] Morozan A, Jousselme B, Palacin S (2011) Low-platinum and platinum-free catalysts for the oxygen reduction reaction at fuel cell cathodes. Energy Environ Sci 4:1238-1254

[4] Ren Q, Wang H, Lu X-F, Tong Y-X, Li G-R (2018) Recent progress on MOF-derived heteroatom-doped carbon-based electrocatalysts for oxygen reduction reaction. Adv Sci 5(3):1700515

[5] Han H, Noh Y, Kim Y, Jung WS, Park S, Kim WB (2019) An N-doped porous carbon network with a multidirectional 
structure as a highly efficient metal-free catalyst for the oxygen reduction reaction. Nanoscale 11:2423-2433

[6] Kim S, Kato S, Ishizaki T, Li OL, Kang J (2019) Transition metal (Fe $\mathrm{Co}, \mathrm{Ni}$ ) nanoparticles on selective amino-n-doped carbon as high-performance oxygen reduction reaction electrocatalyst. Nanomaterials (Basel, Switzerland) 9(5):742

[7] Li Y, Liu D, Gan J, Duan X, Zang K, Ronning M, Song L, Luo J, Chen D (2019) Sustainable and atomically dispersed iron electrocatalysts derived from nitrogen- and phosphorusmodified woody biomass for efficient oxygen reduction. Adv Mater Interfaces 6(4):1801623

[8] Zhu L, Wu J, Zhang Q, Li X, Li Y, Cao X (2018) Chemicalfree fabrication of $\mathrm{N}, \mathrm{P}$ dual-doped honeycomb-like carbon as an efficient electrocatalyst for oxygen reduction. J Colloid Interface Sci 510:32-38

[9] Li X, Gao X, Xu P, You C, Sun W, Wang X, Lin Q, Liao S (2019) Uniform nitrogen and sulfur co-doped carbon bowls for the electrocatalyzation of oxygen reduction. Acs Sustain Chem Eng 7:7148-7154

[10] Deng Y, Chi B, Tian X, Cui Z, Liu E, Jia Q, Fan W, Wang G, Dang D, Li M, Zang K, Luo J, Hu Y, Liao S, Sun X, Mukerjee S (2019) g-C3N4 promoted MOF derived hollow carbon nanopolyhedra doped with high density/fraction of single Fe atoms as an ultra-high performance non-precious catalyst towards acidic ORR and PEM fuel cells. J Mater Chem A 7:5020-5030

[11] Ye Y, Wang B, Liu G, Xu L, Xia J, Li H (2019) fe2o3 nanoparticles modified 2D N-doped porous graphene-like carbon as an efficient and robust electrocatalyst for oxygen reduction reaction. Chemistryselect 4:4131-4139

[12] Marbaniang P, Patil I, Lokanathan M, Parse H, Sesu DC, Ingavale S, Kakade B (2018) Nanorice-like structure of carbon-doped hexagonal boron nitride as an efficient metalfree catalyst for oxygen electroreduction. Acs Sustain Chem Eng 6:11115-11122

[13] Niu H-J, Zhang L, Feng J-J, Zhang Q-L, Huang H, Wang A-J (2019) Graphene-encapsulated cobalt nanoparticles embedded in porous nitrogen-doped graphitic carbon nanosheets as efficient electrocatalysts for oxygen reduction reaction. J Colloid Interface Sci 552:744-751

[14] Zhao Y, Wan J, Yao H, Zhang L, Lin K, Wang L, Yang N, Liu D, Song L, Zhu J, Gu L, Liu L, Zhao H, Li Y, Wang D (2018) Few-layer graphdiyne doped with sp-hybridized nitrogen atoms at acetylenic sites for oxygen reduction electrocatalysis. Nat Chem 10:924-931

[15] Lu Y, Wen X, Chen X, Chu PK, Tang T, Mijowska E (2019) Nitrogen-doped porous carbon embedded with cobalt nanoparticles for excellent oxygen reduction reaction. J Colloid Interface Sci 546:344-350
[16] Cheng Y, He S, Lu S, Veder J-P, Johannessen B, Thomsen L, Saunders M, Becker T, De Marco R, Li Q, Yang S-Z, Jiang SP (2019) Iron Single atoms on graphene as nonprecious metal catalysts for high-temperature polymer electrolyte membrane fuel cells. Adv Sci 6(10):1802066

[17] Xiao M, Zhu J, Ma L, Jin Z, Ge J, Deng X, Hou Y, He Q, Li J, Jia Q, Mukerjee S, Yang R, Jiang Z, Su D, Liu C, Xing W (2018) Microporous framework induced synthesis of singleatom dispersed Fe-N-C acidic ORR catalyst and its in situ reduced $\mathrm{Fe}-\mathrm{N}-4$ active site identification revealed by X-ray absorption spectroscopy. Acs Catal 8:2824-2832

[18] Gong K, Du F, Xia Z, Durstock M, Dai L (2009) Nitrogendoped carbon nanotube arrays with high electrocatalytic activity for oxygen reduction. Science 323:760-764

[19] Xiong W, Du F, Liu Y, Perez A Jr, Supp M, Ramakrishnan TS, Dai L, Jiang L (2010) 3-D carbon nanotube structures used as high performance catalyst for oxygen reduction reaction. J Am Chem Soc 132:15839-15841

[20] Yu D, Zhang Q, Dai L (2010) Highly efficient metal-free growth of nitrogen-doped single-walled carbon nanotubes on plasma-etched substrates for oxygen reduction. J Am Chem Soc 132:15127-15129

[21] Wang S, Yu D, Dai L (2011) Polyelectrolyte functionalized carbon nanotubes as efficient metal-free electrocatalysts for oxygen reduction. J Am Chem Soc 133:5182-5185

[22] Sun L, Luo Y, Li M, Hu G, Xu Y, Tang T, Wen J, Li X, Wang L (2017) Role of pyridinic-N for nitrogen-doped graphene quantum dots in oxygen reaction reduction. J Colloid Interface Sci 508:154-158

[23] Lai L, Potts JR, Zhan D, Wang L, Poh CK, Tang C, Gong H, Shen Z, Lin J, Ruoff RS (2012) Exploration of the active center structure of nitrogen-doped graphene-based catalysts for oxygen reduction reaction. Energy Environ Sci 5:7936-7942

[24] Zhang X, Mollamahale YB, Lyu D, Liang L, Yu F, Qing M, Du Y, Zhang X, Tian ZQ, Shen PK (2019) Molecular-level design of $\mathrm{Fe}-\mathrm{N}-\mathrm{C}$ catalysts derived from $\mathrm{Fe}$-dual pyridine coordination complexes for highly efficient oxygen reduction. J Catal 372:245-257

[25] Zhou X, Qiao J, Yang L, Zhang J (2014) A review of graphene-based nanostructural materials for both catalyst supports and metal-free catalysts in PEM fuel cell oxygen reduction reactions. Adv Energy Mater 4(8):1301523

[26] Deng Y, Chi B, Li J, Wang G, Zheng L, Shi X, Cui Z, Du L, Liao S, Zang K, Luo J, Hu Y, Sun X (2019) Atomic Fedoped mof-derived carbon polyhedrons with high activecenter density and ultra-high performance toward PEM fuel cells. Adv Energy Mater 9(13):1802856

[27] Deng D, Pan X, Yu L, Cui Y, Jiang Y, Qi J, Li W-X, Fu Q, Ma X, Xue Q, Sun G, Bao X (2011) Toward N-doped 
graphene via solvothermal synthesis. Chem Mater 23:1188-1193

[28] Niu W, Li L, Liu X, Wang N, Liu J, Zhou W, Tang Z, Chen S (2015) Mesoporous N-doped carbons prepared with thermally removable nanoparticle templates: an efficient electrocatalyst for oxygen reduction reaction. J Am Chem Soc 137:5555-5562

[29] Cong H-P, Wang P, Gong M, Yu S-H (2014) Facile synthesis of mesoporous nitrogen-doped graphene: an efficient methanol-tolerant cathodic catalyst for oxygen reduction reaction. Nano Energy 3:55-63

[30] Sa YJ, Seo D-J, Woo J, Lim JT, Cheon JY, Yang SY, Lee JM, Kang D, Shin TJ, Shin HS, Jeong HY, Kim CS, Kim MG, Kim T-Y, Joo SH (2016) A general approach to preferential formation of active $\mathrm{Fe}-\mathrm{N}-\mathrm{x}$ sites in Fe-N/C electrocatalysts for efficient oxygen reduction reaction. J Am Chem Soc 138:15046-15056

[31] Wen Z, Ci S, Zhang F, Feng X, Cui S, Mao S, Luo S, He Z, Chen J (2012) Nitrogen-enriched core-shell structured Fe/ Fe3C-C nanorods as advanced electrocatalysts for oxygen reduction reaction. Adv Mater 24:1399-1404

[32] Lin L, Zhu Q, Xu A-W (2014) Noble-metal-free Fe-N/C catalyst for highly efficient oxygen reduction reaction under both alkaline and acidic conditions. J Am Chem Soc 136:11027-11033

[33] Xu Y, Sheng K, Li C, Shi G (2010) Self-assembled graphene hydrogel via a one-step hydrothermal process. ACS Nano 4:4324-4330

[34] Zou B, Wang XX, Huang XX, Wang JN (2015) Continuous synthesis of graphene sheets by spray pyrolysis and their use as catalysts for fuel cells. Chem Commun 51:741-744

[35] Zhou W, Zhou J, Zhou Y, Lu J, Zhou K, Yang L, Tang Z, Li L, Chen S (2015) N-doped carbon-wrapped cobalt nanoparticles on $\mathrm{N}$-doped graphene nanosheets for high-efficiency hydrogen production. Chem Mater 27:2026-2032

[36] Yang W, Liu X, Yue X, Jia J, Guo S (2015) Bamboo-like carbon nanotube/Fe3C nanoparticle hybrids and their highly efficient catalysis for oxygen reduction. J Am Chem Soc 137:1436-1439
[37] Zhou X, Bai Z, Wu M, Qiao J, Chen Z (2015) 3-Dimensional porous $\mathrm{N}$-doped graphene foam as a non-precious catalyst for the oxygen reduction reaction. J Mater Chem A $3: 3343-3350$

[38] Zhou X, Tang S, Yin Y, Sun S, Qiao J (2016) Hierarchical porous $\mathrm{N}$-doped graphene foams with superior oxygen reduction reactivity for polymer electrolyte membrane fuel cells. Appl Energ 175:459-467

[39] Zhang J, Chen J, Luo Y, Chen Y, Wei X, Wang G, Wang R (2019) Sandwich-like electrode with tungsten nitride nanosheets decorated with carbon dots as efficient electrocatalyst for oxygen reduction. Appl Surf Sci 466:911-919

[40] Lezanska M, Olejniczak A, Pacula A, Szymanski G, Wloch J (2014) The influence of microporosity creation in highly mesoporous $\mathrm{N}$-containing carbons obtained from chitosan on their catalytic and electrochemical properties. Catal Today 227:223-232

[41] Lee J-S, Park GS, Kim ST, Liu M, Cho J (2013) A highly efficient electrocatalyst for the oxygen reduction reaction: $\mathrm{N}$-doped ketjenblack Incorporated into $\mathrm{Fe} / \mathrm{Fe} 3 \mathrm{C}$-functionalized melamine foam. Angew Chem Int Ed 52:1026-1030

[42] Xiang Q, Yin W, Liu Y, Yu D, Wang X, Li S, Chen C (2017) A study of defect-rich carbon spheres as a metal-free electrocatalyst for an efficient oxygen reduction reaction. J Mater Chem A 5:24314-24320

[43] Chen Y, Ji S, Wang Y, Dong J, Chen W, Li Z, Shen R, Zheng L, Zhuang Z, Wang D, Li Y (2017) Isolated single iron atoms anchored on $\mathrm{N}$-doped porous carbon as an efficient electrocatalyst for the oxygen reduction reaction. Angew Chem Int Ed 56:6937-6941

[44] Xia D, Yang X, Xie L, Wei Y, Jiang W, Dou M, Li X, Li J, Gan L, Kang F (2019) Direct growth of carbon nanotubes doped with single atomic Fe-N-4 active sites and neighboring graphitic nitrogen for efficient and stable oxygen reduction electrocatalysis. Adv Funct Mater 29(49):1906174

Publisher's Note Springer Nature remains neutral with regard to jurisdictional claims in published maps and institutional affiliations. 